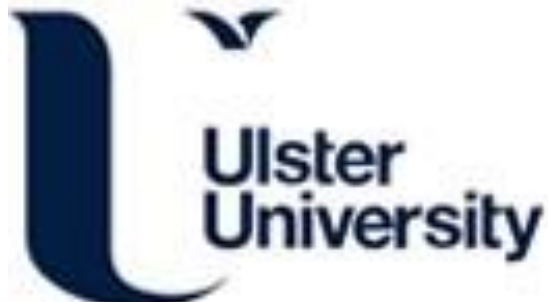

\section{Peer injecting: implications for injecting order and blood-borne viruses among men and women who inject heroin}

McElrath, K., \& Harris, J. (2013). Peer injecting: implications for injecting order and blood-borne viruses among men and women who inject heroin. Journal of Substance Use, 18(1), 31-45.

https://doi.org/10.3109/14659891.2012.716901

Link to publication record in Ulster University Research Portal

Published in:

Journal of Substance Use

Publication Status:

Published (in print/issue): 29/01/2013

DOI:

10.3109/14659891.2012.716901

\section{Document Version}

Publisher's PDF, also known as Version of record

\section{General rights}

Copyright for the publications made accessible via Ulster University's Research Portal is retained by the author(s) and / or other copyright owners and it is a condition of accessing these publications that users recognise and abide by the legal requirements associated with these rights.

\section{Take down policy}

The Research Portal is Ulster University's institutional repository that provides access to Ulster's research outputs. Every effort has been made to ensure that content in the Research Portal does not infringe any person's rights, or applicable UK laws. If you discover content in the Research Portal that you believe breaches copyright or violates any law, please contact pure-support@ulster.ac.uk. 
See discussions, stats, and author profiles for this publication at: https://www.researchgate.net/publication/236173414

Peer injecting: Implications for injecting order and blood-borne viruses among men and women who inject heroin

Article in Journal of Substance Use · February 2013

DOI: 10.3109/14659891.2012.716901

CITATIONS

5

2 authors:

Karen Mcelrath

Florida State University

16 PUBLICATIONS 502 CITATIONS

SEE PROFILE
Ulster University

4 PUBLICATIONS 51 CITATIONS

SEE PROFILE 


\title{
Peer injecting: implications for injecting order and blood-borne viruses among men and women who inject heroin
}

\author{
KAREN MCELRATH \& JULIE HARRIS \\ School of Sociology, Social Policy E Social Work, Queen's University, Belfast, Northern Ireland
}

\begin{abstract}
A large body of research has highlighted practices and rituals that characterise injecting drug use and behavioural and environmental risks that can contribute to the transmission of blood-borne viruses. Compared with other injecting practices, considerably less is known about peer injecting, i.e. receiving or giving injections, particularly the social context in which it occurs. In this article, we explore peer injecting and injecting order at initiation into injecting drug user (IDU) and during subsequent injection episodes. Using data from semi-structured interviews, we highlight the experiences of 41 males and females who had received injections from other IDUs. Respondents were recruited through various strategies, largely chain referral. The results suggest gendered similarities as well as differences in terms of peer injecting, the order of injection and micro-risk contexts for blood-borne viruses.
\end{abstract}

Keywords: Gender, injecting drug use, injecting order, assisted injection, peer injecting

\section{Introduction}

Considerable research has described behaviours among injecting drug users (IDUs) that can pose risk for hepatitis $\mathrm{C}$ and $\mathrm{HIV}$ infection. These behaviours include the loaning and borrowing of injecting equipment (Chitwood et al., 2000; Hagan et al., 2001; De et al., 2007), frontloading and backloading (Grund et al., 1991; Jose et al., 1993; Stark et al., 1996), booting/flushing and other needle/syringe rituals (Pates et al., 2001; McElrath, 2006; Paintsil et al., 2010). IDU often occurs within dyads or small groups, micro-environments that can heighten the risk for bloodborne viruses because of a greater likelihood of blood-to-blood among dyad or group members. In this article, we focus on another injecting practice in which IDUs often engage, i.e. peer injecting, which we define as receiving injections from or giving injections to another IDU.

\section{Peer injecting}

The injecting process is generally more complicated than other routes of administering drugs; thus, individuals are usually taught how to inject by more experienced injectors. Indeed, the

\footnotetext{
Correspondence: Karen McElrath, School of Sociology, Social Policy \& Social Work, Queen's University, Belfast BT71NN,
} Northern Ireland. Tel: +440289097 3551. Fax: +440289097 3943. E-mail: k.mcelrath@qub.ac.uk 
first injection is rarely self-administered, which means that the process is facilitated by others and therefore occurs within a socially interactive context (Bryant \& Treloar, 2007; Frajzyngier et al., 2007; Harocopos et al., 2009; Rhodes et al., 2011). While there is a growing body of research into first injection, scholars have noted that this literature is largely epidemiological (Sánchez et al., 2006).

Following initiation into IDU or the early stage of the injecting career, many individuals begin to self-inject. However, some individuals never learn how to self-inject or never feel comfortable injecting themselves. Others cannot self-inject because of withdrawal symptoms, venous or other health problems (Carlson, 2000; Wood et al., 2003; Fairbairn et al., 2010) and may consistently or periodically rely on other individuals to inject them. Thus, receiving injections from others can occur among IDU initiates, novices as well as long-term users. This practice has been described as "injection assistance" (Robertson et al., 2010), "assisted injection/injecting” (Wand et al., 2009; Fairbairn et al., 2010; Lloyd-Smith et al., 2010), "requiring help injecting" (Wood et al., 2003; O'Connell et al., 2005), "receiving help injecting" (Robertson et al., 2010) and "peer injecting" (Wright et al., 2007). The extent of receiving injections is not well known; however, two studies found that approximately onequarter of IDUs reported seeking assistance with injecting (Robertson et al., 2010) or providing assistance with injections during the 6-month period prior to interview (Fairbairn et al., 2006). A third study found that $41.3 \%$ of IDUs had required help with injecting during the past 6 months (O'Connell et al., 2005). The measures used in these studies were likely to capture receiving and giving injections, as well as other kinds of injecting assistance.

Receiving help with injecting has been found to contribute to the transmission of hepatitis $\mathrm{C}$ virus (HCV) (Wand et al., 2009) and HIV (O'Connell et al., 2005). The practice can increase the likelihood of blood-to-blood contact not only through contaminated injecting equipment but also through physical contact during the giving and receiving of injections (Carruthers, 2003). Some injectors have reported accidental "sharing" of syringes while receiving injections (Fairbairn et al., 2010), and peer injectors have been found to be significantly more likely than other IDUs to loan needles/syringes, binge inject and attend shooting galleries (Fairbairn et al., 2006), and behaviours that have been identified as factors that contribute to blood-borne viruses (Shah et al., 1996; Miller et al., 2006).

Receiving injections from other IDUs can occur in different contexts and appear to vary in terms of the social distance between the recipient and provider of injections. For example, the recipient and the peer injector may be loosely connected through injecting networks, whereby recipients of injection offer money or drugs in exchange for being injected. These providers of injections have been described as "hit doctors"1 (Fairbairn et al., 2010) or "injection doctors" (Carlson, 2000) who are sought out because they are perceived to have injecting expertise (Carlson, 2000; Robertson et al., 2010). The social role of hit doctor can be embedded within drug scenes and attached to particular settings, e.g. shooting galleries (Friedman et al., 2002), and hit doctors are used extensively in some locales. For example, a respondent in Carlson's (2000) ethnographic study reported injecting between 8 and 15 people daily in exchange for cash and a place to inject. Khan et al. (2009) identified 34 urban and rural injecting locations in Sargodha, Pakistan, where two or three street injectors provided daily injections to 15-16 people. The heavy reliance on street injectors in that study was linked to wider drug market factors, e.g. high-purity heroin, drug trafficking routes, as well as individual factors, e.g. relative inexperience with injecting among the majority of the sample.

Alternatively, the recipient and provider of injections can be friends who are members of the same social network whereby the peer injector may or may not be reimbursed with cash or drugs. In other contexts, the two individuals are partners or significant others who have an 
intimate relationship that was established prior to injection initiation or during the injecting career. Studies have described the importance of gender and gendered dynamics that characterise initiation into IDU. For example, some research has found that females and males are likely to be injected by males at initiation (Kermode et al., 2007). Although earlier research found that women tend to be first injected by a (male) sex partner (Crofts et al., 1996; Sherman et al., 2002), the relationship between female initiates and peer injectors has been found to differ across geographic areas (Tompkins et al., 2005), with an increasing number of reports highlighting women's role in initiating other women into IDU (Doherty et al., 2000; Bryant \& Treloar, 2007).

Other research has focused on gender and receiving injections among IDUs with relatively long injecting histories. For example, studies have shown that females are significantly more likely than males to require help with injecting or to engage in assisted injecting (Wood et al., 2003; O’Connell et al., 2005; Wand et al., 2009; Robertson et al., 2010). These gender differences might result from unequal power relationships that can characterise the social context of injecting, venous differences between men and women (Kral et al., 1999), frequency of receiving or giving injections (Wand et al., 2009) and/or disparate knowledge of the injecting process (Treloar et al., 2003; Wood et al., 2003). Although the previous research tends to suggest that females are more likely than males to require help with injecting, findings from a social epidemiological study suggest that males and females were equally likely to provide injections during the 6 months prior to the interview (Fairbairn et al., 2006).

\section{Peer injecting and the order of injecting}

The setting that characterises peer injecting involves a minimum of two people, and the person who injects another IDU might also self-inject in the same setting. This kind of peer injecting suggests that injecting is ordered, i.e. one injection follows and precedes another. Peer injectors who inject first can pass on blood particles to the recipient of injection who is injected second. If the peer injector injects second, the blood spill from the recipient of injection can be passed on to the peer injector. Thus, the order of injecting in these settings can further escalate the risk for transmission of blood-borne viruses. This risk is intensified when the same injecting equipment (e.g. needle, syringe, filter, cooker, water and tourniquet) is used, but can also occur through other blood-to-blood contact that occurs during injections that are given or received by another.

Research that focuses on the order of injecting suggests a complex picture whereby injecting order appears to vary over the injecting career and across injecting settings. At initiation, women IDUs have been reported of being injected by an IDU after she/he self-injects (Tompkins et al., 2005), although the same injecting order might also occur among male initiates. As IDUs progress through an injecting career, the order of injecting appears to be affected by multiple factors and can change depending on the social context as well as the "capital" that IDUs bring to the scene (Crisp et al., 1997, 1998). In general, Crisp et al. (1997) found that the first injection was reserved for the individual who possessed or owned the needle/syringe, particularly when they also had purchased the drugs (see also Tompkins et al., 2005). In a few instances, individual factors (e.g. assertiveness, aggressiveness, knowing and sharing whether a group member was HIV antibody positive) affected injecting order even when individuals did not possess needles/syringes or purchase the drugs. The authors found that gender had no consistent effect on the order of injecting; females injected first in some settings (males being chivalrous) and second in other settings (females as subordinate). 
Both contexts are linked to traditional gender norms and gender role expectations. Crisp et al. (1997, p. 283) did not report extensively on the link between peer injecting and order of injecting but noted that that majority of the 32 respondents reported that peer injectors tended to inject first. A second qualitative study was conducted in England and focused on the experiences of 45 female IDUs in contact with drug or health services (Tompkins et al., 2005, 2006). Those authors suggested that injecting order also is affected by a range of situational and contextual factors, including the severity of withdrawal, the level of intoxication of the injector, inexperience of the person being injected and the nature of social and sexual relationships among the persons present.

\section{Aims of the study}

Peer injecting appears to be a relatively common practice at initiation and at various stages of the injecting career. When peer injectors self-inject within the same setting, the practice is likely to necessitate a particular injecting order that can escalate risk for blood-borne viruses. The purpose of this study is to explore the context of receiving injections from other IDUs at initiation and during subsequent stages of the injecting career. We also address the order of injecting as it relates to IDUs who are peer injected. We focus on the experiences of male and female IDUs in order to explore the role of gender differences and gendered dynamics as they relate to these practices.

\section{Background}

The available public health and police indicators suggest that problem heroin use and injecting began to surface in Northern Ireland during the mid-1990s to late 1990s, relatively later than other western European countries. Although data are not widely available from earlier decades, indicators suggest that individuals experiencing heroin dependence rarely came to the attention of medical professionals or treatment services during the 1970s and 1980s (Murray, 1994). The large-scale presence of police and British army, frequent stops and searches and some of the most sophisticated surveillance systems in Europe would have probably uncovered a heroin market that had once existed (McElrath, 2004). Problem heroin use and IDU began to surface during the mid-1990s to late 1990s, coinciding with the progress towards peace in Northern Ireland (McElrath, 2004). In 2001, the number of problem heroin users was estimated to be 828 (95\% CI: 695-1018) (McElrath, 2002). Hay et al. (2006) found an estimated 1395 opiate users (including problem heroin users) in Northern Ireland during 2004, but substantially lower prevalence rates compared to England, Scotland and the south of Ireland. Pharmacy-based needle/syringe exchange schemes were introduced in Northern Ireland during 2001, and substitute prescribing (methadone and high-dose buprenorphine) became available in 2004 .

The study site was the Eastern Health and Social Services Board (EHSSB) area, a geographic area that includes Belfast, the largest city in Northern Ireland. Near the time of the study, EHSSB claimed the largest estimated number of opiate users in Northern Ireland (1.68 per 1000 people aged 15-64 years) (Hay et al., 2006), as well as the largest number of individuals registered by medical professionals in the region's register of "addicts" (Department of Health, Social Services \& Public Safety, 2011). Qualitative research into IDU in Northern Ireland previously found that IDU respondents in this health board area 
had injected more frequently, were more likely to inject stimulants, had longer histories of injecting, knew substantially more IDUs with hepatitis $C$ infection and were less likely to be engaged with treatment services compared to IDUs in other health and social service board areas (McElrath \& Jordan, 2005).

\section{Method}

Data presented in this article are a subset from a larger study that focuses on gender, risk environments and transitions to injecting among 54 adult men and women (Harris, forthcoming). All respondents had injected illicit drugs (namely heroin), or had smoked or sniffed heroin within 4 weeks prior to the interview. Data were collected between 2008 and 2010, primarily within the Belfast region. In this article, we focus on the subset of respondents who had received injections from another IDU $(N=41)$, either during initiation or subsequently during the injecting career.

Multiple recruitment strategies were used in an attempt to include a range of respondents with diverse drug histories and different socio-demographic backgrounds. Sample characteristics were monitored frequently and targeted sampling was introduced when particular types of respondents appeared to be under-represented. The study was advertised in hostels, three pharmacy-based needle/syringe exchange schemes and via professional and personal contacts. Snowballing sampling was also utilised and attracted the highest number of respondents with 15 chains established. Drug outreach workers also helped with recruitment, which resulted in the participation of five other respondents.

Data were collected through semi-structured interviews that focused on initiation into heroin use and injecting, patterns of use, transitions in and out of injecting and social contexts of use. Interviews were digitally recorded, lasted between 60 and 150 minutes and were conducted by the second author. Interviews were conducted in private settings, including university offices, drug outreach premises and in a local hostel. Considerable time was taken to establish rapport with respondents before, during and after each interview. Experiences were shared and interviewer's self-disclosure was utilised when necessary. Each participant was reimbursed $£ 20$ as an acknowledgement of their time and travel expenses to/from the interview, and the second author transcribed the interview data. Ethical approval was obtained from four bodies: (1) Research Ethics Committee, School of Sociology, Social Policy and Social Work, Queen's University, (2) Research Governance, Queen's University, (3) the Belfast Health Trust, and (4) the Office for Research Ethics for Northern Ireland. Strict ethical protocols were followed. Respondents were provided with information about the study and time was taken to fully explain the purposes of the research. Written consent was obtained prior to the interview and assurances were provided in regard to anonymity and confidentiality.

\section{Analysis}

The analytical approach commenced with several reads of the interview transcripts, noting emerging themes and categories, and developing coding schemes. Preliminary patterns relating to peer injecting and order of injecting were analysed, followed by a system of corroboration and comparison with other cases. The thematic framework was refined by searching the interview data for variations in peer injecting experience. Segments of text were tagged and integrated under the core themes and then refined further into sub-themes, 
e.g. gender and gendered contexts. We explored dominant patterns, socio-environmental conditions where patterns remained as well as outliers.

Member validation was provided to respondents who were provided the opportunity to read their interview transcript and review selected analytical findings. This form of validation appeared to further enhance rapport and, in turn, helped to improve the credibility and validity of the research by ensuring that the findings presented a relevant and acceptable interpretation of the respondents' experiences (Karnieli-Miller et al., 2009).

\section{Results}

Approximately three-quarters of the sample $(N=41)$ reported receiving injections from another IDU. ${ }^{2}$ This sub-sample included 14 females and 27 males, whose ages ranged from 20 to 54 years $($ mean $=33$; median $=31)$. The average age of initiation into IDU was 20 years, with a range of 15-33 years. The duration of injecting spanned from 1 month to 25 years.

\section{Initiation}

The majority of male and female respondents were injected by males at initiation, and females were more likely than males to be injected by a partner (females $=50 \%$; males $=11 \%$ ). Nine male and female respondents were first injected by females, and respondents' reports suggested that female peer injectors had considerable experience with injecting and were wellconnected to drug networks. Both males and females recalled their lack of injecting knowledge at initiation:

She [partner] had called round to my house and she got me quite a wee bit of it [heroin] and she done the business. She prepared it and everything and then she injected me with it. So that was basically my first time and then she had given me the rest of it of what she had got for me but I wasn't aware of getting needles or anything and all the rest of it [other injecting equipment, the injecting process], so I didn't really know what to do with the rest of the stuff then. (Male, late 20s)

Three respondents were first injected by male or female family members whose injecting histories tended to normalise injecting for these respondents. A female recalled being injected first by her mother who reportedly tried to "help" when her daughter experienced trauma:

Well I was 16 years of age and I got pregnant at 15 and then I lost the baby at 16 and my Mum was an addict so the best way for my Ma to try and help me was to give me an injection of heroin. (Female, mid-20s)

In contrast with previous research that highlighted the role of "dominant [male] partners" (Tompkins et al., 2005, p. 27) or persuasion by others to initiate IDU (Frajzyngier et al., 2007), we found little evidence of respondents being coerced or persuaded into injection, even when they had smoked heroin for lengthy periods of time. Indeed, respondents recalled how some peer injectors were reluctant to inject them (see also Rhodes et al., 2011) and several females as well as males noted how they talked to other IDUs into injecting them. Reluctance on the part of the peer injector appeared to be influenced by peers' interest in trying to protect would-be initiatives from stigmatised identities and the health risks 
associated with injecting. However, most male and female respondents were proactive, demonstrating agency in their quest to be injected:

She didn't really want me to doing it, but I talked her into doing it. (Male, early 40s)

I eventually talked someone into it. No one wanted to do it for me [and] I didn't know how to inject myself at the time. But I eventually talked someone into doing it, who I think to this day, the person still feels guilt-ridden about it. But again it was my choice at the end of it. (Female, early 30s)

Only one respondent in this study described an initiation scenario that might be described as being influenced by coercion or persuasion from others. He recalled how he was encouraged to inject by his female partner and another male who was present at the scene:

It [injecting] came from basically pressure from the person [partner] who I was with, they wanted me to inject and I didn't want to inject. I was quite happy to smoke it. There was three of us and she [partner] was like, 'Come on and inject it' and he was like, 'Yeah, come on and we'll try it'. And I was like, 'Nah man, I don't want to' and then the next thing was that it was there and it was happening and that's how it sort of happened. (Male, early 30s)

The majority of respondents (28 out of 41 ) reported injecting before the peer injector at initiation. Of the 14 females who were injected by another IDU at initiation, approximately half ( 8 out of 14 ) reported that they were injected first, that is, before the peer injector. In contrast, three-quarters of males (20 out of 27) reported being injected first during initiation. These results suggest that the relationship between the initiate and the peer injector helped shape injecting order. Specifically, female initiates tended to inject second when the peer injector was a partner, largely because of their intimate relationship with the peer injectors.

\section{Continuation of peer injecting}

The majority of respondents ( 31 out of 41 ) continued to be injected by another IDU as they progressed through the injecting career. In general, however, respondents tended to vacillate between self-injecting and receiving injections from others. Although the majority of female respondents (11 out of 14) reported self-injecting within 6 months of initiation, they also received injections from other IDUs:

You see trying to rely on other people to get the drugs as well and then relying on other people to do it? I learnt pretty quickly how to inject myself. But in saying that there, my veins now . . . I've been doing it [injecting] for about ten years now and my veins are bolluxed [damaged, ruined] now. Absolutely bolluxed. (Female, early 30s)

A number of males also continued to receive injections from another IDU; however, all but one male learned to self-inject within 6 months of initiation. Moreover, approximately onethird of males self-injected during the second injection episode, whereas only 2 of 14 females reported self-injecting during the next injecting session.

Following initiation, respondents noted that they continued to rely on males (partners, acquaintances or friends) to inject them; however, some respondents relied on or preferred female peer injectors. Respondents recalled using more than one peer injector during the same setting: 
We were all in a squat and it was just when I got out of prison. We all shot in there and we had two spoons there. I got [male friend] to do me. She [female friend] couldn't find a vein. She used to do everybody ... and was just looking for a vein but couldn't find one. She was going mental [and] was going at it for about an hour. [Male friend eventually] found the vein. (Female, early 30s)

Similar to previous research findings, data from this study suggest that withdrawal symptoms and venous problems were the primary reasons for most subsequent peer injections. This pattern held for both male and female respondents:

Nah, they [male friends/acquaintances] had their hit first. They always had to get their gear into them first. You had to wait. You were the second person because you didn't know how to bang up [inject]. You were standing there with your needle waiting for them to hit you up. (Male, early 30s)

I used to keep mine [drugs] in a wee tin pencil case and a couple of needles and citric and you're wee things of water. I would keep it all in the thing . . But all the time somebody would have to hit me up, 'cause I've never went myself [never self-injected]. Well I've went myself when I started you know when my veins, you could see them. But my veins only lasted about six months. That was it, they were gone. Where as well I didn't know what I was doing it, I was just sticking it everywhere so I was. Didn't know where I was going and once I actually put it in here [points to arm]. Then after that I started getting afraid to hit up, so then I was asking other people to do it for me and it was flipping going in my wrists, everywhere. I've still got the scars [shows scars on wrists and arms]. (Female, late 30s)

Although most respondents reported being careful about their choice of peer injector, respondents who were experiencing withdrawal or in the company of less experienced peer injectors often were less selective. In some instances, claims about cautiousness were not substantiated by partners who were present during some interviews:

R1: I'm very meticulous about the people who inject me. I wouldn't just let anybody do it. (Male, early 30s)

R2: Well that's not really true. If you were sick it would be whoever. (Female partner, early 30s)

R1: No, if I was sick I would go to a certain person who I know would do it for me.

R2: That would be for the last ten years because you haven't been able to inject yourself. [He's] always had to buy two bags.

$\mathrm{R} 1$ : One for them [the peer injector] and one for me ... I would get the stuff [heroin] and I would make a phone call to the two or three people who I knew, that I could trust and go to them. One of them was like a heroin addict then, so the chances of him saying no to you were slim to none. So I had three trusted people who I know I could phone and at least one of them would definitely say, 'Yes, come on round'. . My veins are in good condition because other people do it for me. They take more care, whereas if you're doing it yourself you could hurt yourself more.

The data show that injecting order fluctuated among males and females during subsequent peer injections. That is, when asked about injecting order during subsequent peer injections, most respondents ( 21 out of 31 ) reported that they "sometimes" were the first to be injected 
during these episodes. Injecting order was influenced by multiple micro- and macrolevel factors, including the availability of heroin:

They [male friends/acquaintances] just wanted the hit first. I mean in [place in NI], there would maybe be times [...] when you would have to wait three days [for heroin]. Four days for some of it, you know? Even waiting longer than that and when you're waiting that length of time, whenever you do get some, you don't want to be bothered doing somebody else you know? You want to do your own first. (Male, mid-40s)

Both male and female respondents demonstrated some degree of power and control over the injecting order. Their degree of influence depended on their relationship with other IDUs in the setting, as well as which party bought or owned the drugs. These factors often took precedent over an injector's withdrawal symptoms:

He [partner] just couldn't wait [withdrawal] and I'm going like, 'Now hold on a second, I don't want to bring this to account, but I bought it. It's my money and I want to hit up first before you get so out of it and you miss'. And I said 'No, if I buy it then I get to hit up first', and I always did buy it. (Female, late 30s)

Females who were injected by partners recalled "going second," because partners were experiencing withdrawal symptoms. A few female respondents questioned male partners' justifications for insisting on injecting first:

I: So it was really to stop him from withdrawal?

$\mathrm{R}$ : Yeah, something to stop him shaking so that he would be steady with me. That's what he said and I could sort of understand, and it was true some of the time, but it wasn't true all of the time. He just couldn't wait. (Female, late 30s)

The majority of females and about half the males reported paying an IDU to inject them, and payment was nearly always made with drugs as opposed to cash. Males were more likely than females to report never having to provide cash or drugs in exchange for being injected. A female respondent who reported always being injected by other IDUs described an exchange:

You would have had to give them a bit in the needle, yeah. They would have been like, 'What are you going to give me out of it?' And I would have just put a bit of powder out and went, 'Right, there. And that's all I've got.' But money? No. (Female, early 30s)

At times, however, peer injectors had considerable access to drugs and did not expect compensation for peer injecting. This pattern was observed primarily among same-sex friendships:

I: Did you have to give anything to the person injecting you?

R: Aye, like sort them out. Yeah, I would have had to give them about half a bag [of heroin], depending on who it was. Just say they had their own [heroin] . . Just say I used to go round to my mate [female friend] but she sold it as well so she didn't mind, know what I mean? I would usually have given [female friend] a pipe or whatever, but she didn't care about a hit cause she had her own [heroin]. Or else I would have put a bit of crack into her thing, and then she would have a snowball, you know mixing it? And we would have done it that way. 
I: So it just depended on who you were with?

R: Yeah.

I: Aye, I can see that. Did you have to give anything to the person injecting you?

R: Aye, like sort them out. Yeah, I would have had to give them about half a bag. It depending on who it was. Just say they had their own. Just say I used to go round to my mate [female friend] but she sold it as well so she didn't mind [injecting me], know what I mean? I would usually have given [female friend] a pipe or whatever, but she didn't care about a hit cause she had her own. Or else I would have put a bit of crack into her thing, and then she would have a snowball, you know mixing it? And we would have done it that way.

I: So it just depended on who you were with?

R: Yeah.

Although payment for being injected by an IDU was the norm in this sample, a few respondents reported that they never or rarely paid for this service with either drugs or money. A female reported that nearly all her injections were provided by other IDUs, and that her peer injectors were always male who rarely asked for compensation. She described her relationships with the peer injectors:

The first time it was my ex-partner. Second time it was my present boyfriend, and the other two times it was men that I'd known for years but they had already come on to me anyway. I knew that they wanted to be lovers with me on previous occasions but it never happened but they did end up injecting me. (Female, late 30s)

She continued by describing the negotiation over clean needles/syringes during her quest to be injected by a male IDU. In the excerpt below, she demonstrates control over the exchange with the male peer injector:

Like if they said to me, 'Give us that needle after you', and I says, 'Nah, this is a clean needle. You have hepatitis and I haven't. I'll only give you a run [bit of heroin].' Or, 'I'll give you $£ 20$ or I'll give you a bag'. [They'd say] 'Right, well then go on and give me a bag if you won't give me a needle.' I could have four or five needles but I wasn't going to be telling them that.

Some respondents recalled the difficulties with coordination and dexterity among peer injectors who self-injected first, and then began to experience the effects of heroin before they injected the respondent. In these scenarios, peer injectors sometimes made several attempts to inject the other person, missing veins during the attempts. A female reported that male IDUs always injected before her, "They had to have it. They needed it." The interviewer asked whether the male peer injectors ever missed a vein, while attempting to inject her:

Oh god yeah. You could even see somebody standing and they'd be gouching [nodding off as a result of heroin use; intoxication]. Their eyes would be closed and then somebody would come over and take over and even [my partner] at times, he'd be standing and you'd think his legs were going to buckle underneath him. And then there'd be arguments around hep C, and me going, 'Make sure you use separate equipment'. And him saying, 'But I didn't use that spoon'. And I'm going, 'Well, that's the only spoon that shape 'cause 
I stole it out of [restaurant]' and you've just used it and you're using it with me again'”. (Female, late 30s)

Previous research has also highlighted "gouching" among peer injectors who attempt to administer injections to women (Tompkins et al., 2005). In this study, this experience intensified risk scenarios, particularly when respondents used more than one peer injector:

I: Would the person that was injecting have gone first?

$\mathrm{R}$ : Aye, and I hated it because they were always like, 'Eeow', gouching and they sticking the needle everywhere in my arm and I'm sitting going, 'Fuck sake, I'm busting for a hit'. And I had to say to them, 'Would you open your eyes fuck's sake?' They were just like really gouching out and I couldn't do it [inject] myself, so it was so frustrating, so it was.

I: Did that vary in terms of who you were with? Like if you were with [female friend] would she have done you first?

$\mathrm{R}$ : Aye, most of the time she would have done me first because she would have went [injected] into her groin . . . But she would usually been always really gouched out on gear [heroin]. I was never really one for gouching. I was always up, if you know what I mean. I think that was because of the crack. I never ever felt gouched out, you know? (Female, late 20s)

\section{Discussion}

The findings highlight the layers of risk associated with the peer injecting environment. These layers of risk begin during initiation into IDU when respondents were administered an injection by an IDU who also self-injected. Although the majority of respondents reported that they injected first at initiation, 13 other respondents recalled injecting second, which likely entails greater exposure to blood from the peer injector. Peer injecting commenced because male and female initiates lacked knowledge about the injecting process. Although the majority of respondents learned to self-inject within 6 months of initiating IDU, a few individuals never felt confident with injecting, preferring other IDUs to provide injections for them. For other respondents, peer injecting did not necessarily continue immediately after initiation, rather, it re-surfaced when respondents developed venous problems or experienced withdrawal symptoms that prevented self-injection.

Additional layers of risk were introduced because recipients of injecting utilised several different peer injectors over the injecting career; similar to the various levels of skill among professional phlebotomists, some peer injectors were perceived as better than others. A few respondents recalled being exposed to more than one peer injector in the same injecting setting. In these contexts, peer injectors' incapability to administer injections appeared to be affected by the pharmaceutical effects of heroin. Respondents spoke of peer injectors' several attempts to administer injections. The physical scarring left by some attempts was likely preceded by the presence of blood at the injecting sites. These findings suggest that although peer injectors can introduce risk to injecting settings, they also can be disproportionately exposed to it. Risk environments were also created by peer injectors who experienced withdrawal symptoms prior to injecting, and insisted on self-injecting prior to peer injecting. Observing a peer injector undergo "dope sickness" created anxiety for respondents who wished to inject first due to their own withdrawal effects or concerns over safety. 


\section{Gender and peer injecting}

We found similarities as well as gender differences at initiation. Most males and females actively sought out IDUs to first inject them, despite the initial reluctance of other IDUs. Additionally, most males and females were most likely to be peer injected by a male IDU; however, roughly half of all females were first injected by a male partner, whereas only three males (approximately 10\% of male respondents) were injected by a female partner. Injecting order tended to favour male respondents; however, heterosexual partners who were peer injectors tended to inject first regardless of whether the recipient was male or female. The relatively small number of study participants prevented us from further investigating this pattern among male/female dyads.

Both male and female recipients of injection were affected by the well-being of the peer injector and considered whether peer injectors experiencing withdrawal were more capable than peer injectors who were intoxicated. Additionally, men and women recalled the difficulties associated with frequent attempts to locate peer injectors, and relied on more than one IDU to inject them. However, females were more likely than males to provide drugs in exchange for being peer injected, particularly as they progressed through the injecting career. Although some scholars might view this finding as evidence of a gendered power imbalance, we view it as an example of female injectors' attempt to assert control over their injecting episodes. We suggest that these exchanges tended to influence women's place in the injecting order. Compensating the peer injector meant that women could better justify their choice to inject first, thus diminishing some risk associated with the injecting environment.

Bryant et al. (2010, p. 185) found that a number of female IDUs in their study could not be described as "passive participants," in relation to their drug lifestyle roles. Rather, the authors noted that several females in partnerships with male IDUs were integrated with IDU networks, and solely or jointly involved in drug purchase and preparation for injection. A few females in this study behaved passively or assumed stereotypical gender roles, e.g. expecting to inject second, preferring a male peer injector. However, our findings are more consistent with those of Bryant et al. (2010). As discussed above, several other females proactively asserted themselves with regards to the informal rules around injecting order. Additionally, many females voiced knowledge about some safer injecting practices and this knowledge was considered as they negotiated with peer injectors. Most males and females in this study continued to or subsequently relied on peer injectors not because they lacked knowledge about injecting but because they developed venous problems, and women tended to experience venous problems more quickly than men.

The findings from this study add further weight to the assumption that injecting risk is influenced greatly by social networks and the social context in which it occurs. Harm reduction and prevention efforts that target the behaviours of individual IDUs are unlikely to be effective because they often ignore the role of structural factors and social network influences that contribute to individual behaviours (Neaigus et al., 1994; Rhodes, 2002). Reducing risk around peer injecting requires peer interventions that can be integrated with trusted street outreach workers.

\section{Declaration of interest}

The authors report no conflicts of interest. The authors alone are responsible for the content and writing of the article. 


\section{Acknowledgements}

We extend our thanks to the individuals who participated in the study. We also appreciate the reviewers' comments and their timely response. The study was sponsored by Queen's University Research Governance and the Belfast Health Trust.

\section{Notes}

1. According to Fairbairn et al. (2010), "hit doctors" were initially described in the literature by Murphy \& Waldorf (1991) in their study of San Francisco shooting galleries.

2. The remainder had either always self-injected or had never transitioned from smoking heroin to injecting.

\section{References}

Bryant, J., Brener, L., Hull, P., \& Treloar, C. (2010). Needle sharing in regular sexual relationships: An examination of serodiscordance, drug using practices, and the gendered character of injecting. Drug and Alcohol Dependence, $107,182-187$.

Bryant, J., \& Treloar, C. (2007). The gendered context of initiation to injecting drug use: Evidence for women as active initiates. Drug and Alcohol Review, 26, 287-293.

Carlson, R. (2000). Shooting galleries, dope houses, and injection doctors: Examining the social ecology of HIV risk behaviors among drug injectors in Dayton, Ohio. Human Organization, 59, 325-333.

Carruthers, S. J. (2003). The ins and outs of injecting in Western Australia. Fournal of Substance Use, 8, 11-18.

Chitwood, D. D., Sanchez, J., Comerford, M., Page, J. B., McBride, D. C., \& Kitner, K. R. (2000). First injection and current risk factors for HIV among new and long-term injection drug users. AIDS Care, 12, 313-320.

Crisp, B. R., Barber, J. G., \& Gilbertson, R. (1997). The etiquette of needle sharing. Contemporary Drug Problems, 24, 273-291.

Crisp, B. R., Barber, J. G., \& Gilbertson, R. (1998). The relative importance of factors which influence order of injecting with a shared needle and syringe. AIDS Care, 10, 713-721.

Crofts, N., Louie, R., Rosenthal, D., \& Jolley, D. (1996). The first hit: Circumstances surrounding initiation into injecting. Addiction, 91, 1187-1196.

De, P., Cox, J., Boivin, J., Platt, R. W., \& Jolly, A. M. (2007). The importance of social networks in their association to drug equipment sharing among injection drug users: A review. Addiction, 102, 1730-1739.

Department of Health, Social Services and Public Safety. (2011). Statistics from the Northern Ireland drug addicts index, 2010. Belfast: Author.

Doherty, M. C., Garfein, R. S., Monterroso, E., Latkin, C., \& Vlahov, D. (2000). Gender differences in the initiation of injection drug use among young adults. Fournal of Urban Health, 77, 296-414.

Fairbairn, N., Small., W., Van Borek, N., Wood, E., \& Kerr, T. (2010). Social structural factors that shape assisted injecting practices among injection drug users in Vancouver, Canada: A qualitative study. Harm Reduction fournal, 7, 20.

Fairbairn, N., Wood, E., Small, W., Stolz, J., Li, K., \& Kerr, T. (2006). Risk profile of individuals who provide assistance with illicit drug injections. Drug and Alcohol Dependence, 82, 41-46.

Frajzyngier, V., Neaigus, A., Gyarmathy, V. A., Miller, M., \& Friedman, S. R. (2007). Gender differences in injection behaviours at the first injection episode. Drug and Alcohol Dependence, 89, 145-152.

Friedman, S. R., Kang, S. Y., Deren, S., Robles, R., Colón, H. M., Andia, J., Oliver-Velez, D., \& Finlinson, A. (2002). Drug-scene roles and HIV risk among Puerto Rican injection drug users in East Harlem, New York and Bayamón, Puerto Rico. Fournal of Psychoactive Drugs, 34, 363-369.

Grund, J. P., Kaplan, C. D., Adriaans, N. F., \& Blanken, P. (1991). Drug sharing and HIV transmission risks: The practice of frontloading in the Dutch injecting drug user population. Fournal of Psychoactive Drugs, 23, 1-10.

Hagan, H., Theide, H., Weiss, N. S., Hopkins, Sg., Duchin, J. S., \& Alexander, E. R. (2001). Sharing of drug preparation equipment as a risk factor for hepatitis C. American fournal of Public Health, 91, 42-46.

Harocopos, A., Goldsamt, L. A., Kobrak, P., Jost, J. J., \& Clatts, M. C. (2009). New injectors and the social context of injection initiation. International fournal of Drug Policy, 20, 317-323. 
Harris, J. (forthcoming). Initiations and transitions into injecting drug use: The social and gendered context of risk Ph.D. thesis. Belfast: Queen's University.

Hay, G., Higgins, K., Gannon, M., \& Carroll, C. (2006). Estimating the prevalence of problem opiate and problem cocaine use in Northern Ireland. Glasgow: Centre for Drug Misuse Research, University of Glasgow.

Jose, B., Friedman, S. R., Neaigus, A., Curtis, R., Grund, J. P., Goldstein, M. F., Ward, T. P., \& Dees Jarlais, D. C. (1993). Syringe-mediated drug-sharing (backloading): A new risk factor for HIV among injecting drug users. AIDS, 7, 1653-1660.

Karnieli-Miller, O., Strier, R., \& Pessach, L. (2009). Power relations in qualitative research. Qualitative Health Research, 19, 279-289.

Kermode, M., Longleng, V., Singh, B. C., Hocking, J., Langkham, B., \& Crofts, N. (2007). My first time: Initiation into injecting drug use in Manipur and Nagaland, north-east India. Harm Reduction fournal, 4, 19.

Khan, A. A., Awan, A. B., Qureshi, S. U., Razaque, A., \& Zafar, S. T. (2009). Large sharing networks and unusual injection practices explain the rapid rise in HIV among IDUs in Sargodha, Pakistan. Harm Reduction fournal, 6, 13.

Kral, A. H., Bluthenthal, R. N., Erringer, E. A., Lorvick, J., \& Edlin, B. R. (1999). Risk factors among IDUs who give injections to or receive injections from other drug users. Addiction, 94, 675-683.

Lloyd-Smith, E., Rachlis, B. S., Tobin, D., Stone, D., Li, K., Small, W., Wood, E., \& Kerr, T. (2010). Assisted injection in outdoor venues: An observational study of risks and implications for service delivery and harm reduction programming. Harm Reduction fournal, 7, 6.

McElrath, K. (2002). Prevalence of problem heroin use in Northern Ireland. Belfast: Department of Health, Social Services and Public Safety.

McElrath, K. (2004). Drug use and drug markets in the context of political conflict: The case of Northern Ireland. Addiction Research and Theory, 12, 577-590.

McElrath, K. (2006). Booting and flushing: Needle rituals and risk for bloodborne viruses. Fournal of Substance Use, $11,177-189$.

McElrath, K., \& Jordan, M. (2005). Drug use and risk behaviours among injecting drug users. Belfast: Department of Health, Social Services and Public Safety.

Miller, C. L., Kerr, T., Frankish, J. C., Spittal, P. M., Li, K., Schechter, M. T., \& Wood, E. (2006). Binge drug use independently predicts HIV seroconversion among injection drug users: Implications for public health strategies. Substance Use and Misuse, 41, 199-210.

Murphy, S., \& Waldorf, D. (1991). Kickin' down to the street doc: Shooting galleries in the San Francisco Bay area. Contemporary Drug Problems, 18, 9-29.

Murray, M. (1994) Use of illegal drugs in Northern Ireland. In J. Strang \& M. Gossop (Eds.), Heroin addiction and drug policy: The British system (pp. 134-147). Oxford: Oxford University Press.

Neaigus, A., Friedman, S. R., Curtis, R., Des Jarlais, D. C., Furst, R. T., Jose, B., Stepherson, B., Sufian, M., Ward, T., \& Wright, J. W. (1994). The relevance of drug injectors' social and risk networks for understanding and preventing HIV infection. Social Science and Medicine, 38, 67-78.

O’Connell, J. M., Kerr, T., Li, K., Tyndall, M. W., Hogg, R. S., Montaner, J. S., \& Wood, E. (2005). Requiring help injecting independently predicts HIV infection among injection drug users. Fournal of Acquired Immune Deficiency Syndromes, 40, 83-88.

Paintsil, E., He, H., Peters, C., Lindenbach, B. D., \& Heimer, R. (2010). Survival of hepatitis C virus in syringes: Implication for transmission among injection drug users. Fournal of Infectious Diseases, 202, 984-990.

Pates, R. M., McBride, A. J., Ball, N., \& Arnold, K. (2001). Towards an holistic understanding of injecting drug use: An overview of needle fixation. Addiction Research and Theory, 9, 3-17.

Rhodes, T. (2002). The "risk environment": A framework for understanding and reducing drug related harm. International fournal of Drug Policy, 13, 85-94.

Rhodes, T., Bivol, S., Scutelniciuc, O., Hunt, N., Bernays, S., \& Busza, J. (2011). Narrating the social relations of initiating injecting drug use: Transitions in self and society. International fournal of Drug Policy, 22, $445-454$.

Robertson, A. M., Vera, A. Y., Gallardo, M., Pollini, R. A., Patterson, T. L., Case, P., Nguyen, L., \& Strathdee, S. A. (2010). Correlates of seeking injection assistance among injection drug users in Tijuana, Mexico. American Fournal of Addiction, 19, 357-363.

Sánchez, J., Chitwood, D. D., \& Koo, D. J. (2006). Risk factors associated with the transition from heroin sniffing to heroin injection: A street addict role perspective. Fournal of Urban Health, 83, 896-910.

Shah, S. M., Shapshak, P., Rivers, J. E., Stewart, R. V., Weatherby, N. L., Xin, K. Q., Page, J. B., Chitwood, D. D., Mash, D. C., Vlahov, D., \& McCoy, C. B. (1996). Detection of HIV-1 DNA in needle/syringes, paraphernalia, and washes from shooting galleries in Miami: A preliminary laboratory report. Fournal of Acquired Immune Deficiency Syndromes and Human Retrovirology, 11, 301-306. 
Sherman, S. G., Smith, L., Laney, G., \& Strathdee, S. A. (2002). Social influences on the transition to injection drug use among young heroin sniffers: A qualitative analysis. International fournal of Drug Policy, 13, 113-120.

Stark, K., Müller, R., Bienzle, U., \& Guggenmoos-Holzmann, I. (1996). Frontloading: A risk factor for HIV and hepatitis $\mathrm{C}$ virus infection among injecting drug users in Berlin. AIDS, 10, 311-317.

Tompkins, C., Sheard, L., Wright, N., Howes, N., \& Jones, L. (2005). Women and the peer injecting of illicit drugs: $A$ focus on the implications for practice. Leeds/Mansfield: Leeds North East Primary Care Trust and Nottingham County Drug and Alcohol Action Team.

Tompkins, C. N. E., Sheard, L., Wright, N. M. J., Howes, N., \& Jones, L. (2006). Exchange, deceit and harm: The consequences for women of receiving injections from other drug users. Drugs: Education, Prevention and Policy, 13, 281-297.

Treloar, C., Abelson, J., Crawford, J., Kippax, S., Howard, J., van Beek, I., Copeland, J., \& Weatherall, A. M. (2003). Risk for hepatitis C: Transition and initiation to injecting drug use among youth in a range of injecting drug user networks. Sydney: National Centre in HIV Social Research, University of New South Wales.

Wand, H., Spiegelman, D., Law, M., Jalaludin, B., Kaldor, J., \& Maher, L. (2009). Estimating population attributable risk for hepatitis $\mathrm{C}$ seroconversion in injecting drug users in Australia: Implications for prevention policy and planning. Addiction, 104, 2049-2056.

Wood, E., Spittal, P., Kerr, T., \& Small, W. (2003). Requiring help injecting as a risk factor for HIV infection in the Vancouver epidemic: Implications for HIV prevention. Canadian fournal of Public Health, 94, 355-359.

Wright, N. M. J., Tompkins, C. N. E., \& Sheard, L. (2007). Is peer injecting a form of intimate partner abuse? A qualitative study of the experiences of women drug users. Health and Social Care in the Community, 15, 417-425. 